Tersedia online di: http://ejournal-balitbang.kkp.go.id/index.php/JP
e-mail:jurnalpari@gmail.com
JURNAL PARI
Volume 4 Nomor 2 Desember 2018
p-ISSN: 2502-0730
e-ISSN : 2549-0133

\title{
PERAN HUMAS BRSDM BERDASARKAN PERATURAN MENTERI KELAUTAN DAN PERIKANAN NO.44 TAHUN 2016
}

\author{
Kasmawati \\ Sekretariat Badan Riset dan Sumber Daya Manusia Kelautan dan Perikanan \\ Diterima tanggal : 17 Oktober 2018 Diterima setelah perbaikan : 22 November 2018 \\ disetujui terbit : 20 Desember 2018
}

\begin{abstract}
ABSTRAK
Humas atau Public Relation merupakan kegiatan yang bersentuhan langsung dengan masyarakat/publik dan diharapkan mendapatkan peran yang sangat penting dalam suatu organisasi. Badan Riset dan Sumber Daya Manuia Kelautan dan Perikanan (BRSDM) memiliki tim humas BRSDM yang berada di Sekretariat BRSDM dan dibantu oleh unit kehumasan yang berada di unit kerja lingkup BRSDM sebagai perpanjangan dalam melaksanakan peran kehumasan BRSDM dan pimpinan khususnya. Tugas dan fungsi kehumasan BRSDM, telah di jabarkan pada Peraturan Menteri Kelautan dan Perikanan (Permen KP) yaitu Peraturan Menteri Kelautan dan Perikanan Nomor.6/Permen-KP/2017 tentang Organisasi Dan Tata Kerja Kementerian Kelautan Dan Perikanan dan Peraturan Menteri KP No 44 Tahun 2016 tentang Penyelenggaraan Kehumasan di Lingkungan KKP. Dalam mendukung tugas dan fungsi tim humas harus mengacu pada kedua Permen KP tersebut. Sejauhmana kegiatan kehumasan BRSDM sudah sesuai dengan 2 Permen KP tersebut dalam menjalankan tugas dan fungsi kehumasan.
\end{abstract}

\section{Kata Kunci: Kehumasan, public relation}

\section{ABSTRACT}

As an activity that facilitates direct contacts with the community, public relations plays an important role in an organization. The Marine and Fisheries Research and Human Resource Agency (BRSDM) has the BRSDM public relations team whose office is located in the BRSDM Secretariat. The BRSDM Public Relation Team is supported by a number of public relations staffs from each of the relevant technical units of BRSDM. The duties and functions of the BRSDM PR is officiated by the Minister of Maritime Affairs and Fisheries Regulation (KP Regulation) through the Minister of Maritime Affairs and Fisheries Regulation Number.6 / Permen-KP / 2017 concerning the Organization and Work Procedure of the Ministry of Maritime Affairs and Fisheries and Ministerial Regulation No. 44 of 2016 concerning the Implementation of Public Relations within the KKP. In carrying out the duties and functions of public relations the BRSDM's public relations activities must be in accordance with these two Regulations.

\section{Keywords: Public realtions, public relation}




\section{Pendahuluan}

Instruksi Presiden Jokowi dari Istana Negara 4 Februari 2016 mengatakan bahwa "humas pemerintah harus cepat merespon dan memberikan informasi, harus melibatkan masyarakat dalam program/ kebijakan dan bersinergi dan tidak ego sektoral". Dan saat di Instana Bogor "Humas Pemerintah harus selalu berubah dan beradaptasi secara kreatif mengikuti perkembangan teknologi..". (sumber: Humas Kepresidenan). Dijelaskan betapa pentingnya humas pemerintah dalam menyebarluaskan infomasi kepada publik/masyarakat melalui media cetak dan elektronik.

Masyarakat umumnya ingin mengatahui apa yang dikerjakan, apa yang dihasilkan oleh suatu organisasi, kaitannya dengan memenuhi kepentingannya. Jika suatu organisasi tidak dapat menjelaskan apa yang dilakukan dapat mempengaruhi kinerja organisasi yang mengakibatkan salah pengertian.

Informasi yang diolah menciptakan suatu komunikasi dua arah melalui media yang tersedia baik cetak dan online. Dan informasi yang hendak dihasilkan ke media massa harus mampu menarik minat para pembaca, pemirsa, atau pendengar. Standar ini harus senantiasa diperhatikan oleh setiap praktisi humas yang hendak mempublikasikan pesanpesan humasnya.

Dalam memberikan informasi diperlukan peranan seorang Humas atau biasa disebut public relations (PR) karena humas harus siap memberikan dan menciptakan saling pengertian diantara publik yang terkait di dalamnya, seperti yang dikutip dari The British Institute of Public Relations, yaitu "The deliberate, planned and sustained effort to establish and maintain mutual understanding between an organization and its public. (Upaya yang mantap, berencana dan berkesinambungan untuk menciptakan dan membina pengertian bersama antara organisasi dengan khalayaknya)." (Effendy, 1990 : 134).

Pakar komunikasi mengemukakan pengertian komunikasi diantaranya Komunikasi memungkinkan seseorang untuk mengkoordinasikan suatu kegiatan kepada orang lain untuk mencapai tujuan bersama (Myers, 1987). Dan menurut Katz dan Robert Kahn, Komunikasi adalah pertukaran informasi dan penyampaian makna yang merupakan hal utama dari suatu sistem sosial atau organisasi. Komunikasi adalah suatu proses penyampaian informasi dan pengertian dari satu orang ke orang lain, dan satu satunya cara mengelola aktivitas dalam suatu organisasi adalah melalui proses komunikasi (Ruslan,
1995).

Hasil komunikasi akan menciptakan timbal balik atau respon yang diinginkan. Tim Humas harus memeriksa kelayakan berita dari suatu siaran berita, artikel, atau gambar-gambar (foto/video) yang hendak dipublikasikan sebelum diserahkan ke media massa. Sebuah siaran berita yang baik harus menyajikan informasi yang sama bermutunya dengan yang biasa ditulis oleh para jurnalis.

Humas/Public Relations (PR) merupakan pihak yang paling memahami mengenai publik dari suatu organisasi (perusahaan/lembaga/instansi). Peranan humas dalam suatu organisasi berkaitan dengan tujuan dan fungsi organisasi tersebut dan pencapaian suatu tujuan tersebut.

Fungsi Humas sebagai fungsi manajemen yang mengevaluasi sikap publik, mengidentifikasi kebijaksanaan-kebijaksanaan dan prosedur-prosedur seorang individu atau sebuah organisasi berdasarkan kepentingan publik, dan menjalankan suatu program untuk mndapatkan pengertian dan penerimaan publik (Moore, 2005).

Humas dalam suatu organisasi merupakan bagian integral yang tidak dapat dipisahkan dari suatu kelembagaan dan organisasi. Tingkat keberhasil dapat terlihat apabila berada di bawah pimpinan atau mempunyai hubungan dengan pimpinan tertinggi (pengambil keputusan) pada suatu organisasi/instansi bersangkutan (Ruslan, 1995).

Peran Humas KKP sangat penting dan setiap PNS KKP adalah sebagai humas, sebagai jembatan dan berperan aktif membangun komunikasi antara pemerintah dengan masyarakat dengan menggunakan kanal resmi KKP (media sosial dan website) dalam dalam mensosialisasikan program kerja KKP, pesan ini disampaikan oleh Sekretaris Jenderal KKP pada Rapat Koordinasi Nasional Kehumasan 2017.

Kementerian Kelautan dan Perikanan (KKP) telah diakui dan diperhatikan oleh pimpinan tertinggi dalam menjalankan peran dalam memberikan informasi tentang kelautan dan perikanan Indonesia kepada masyarakat baik Indonesia dan Internasional. Media komunikasi KKP yang dimiliki saat ini dalam bentuk cetak (majalah) dan elektronik (website, media sosial).

Dalam mengatur penyebaran/penyampaian informasi, komunikasi dan kehumasan lingkup KKP telah membuat Peraturan Menteri Kelautan dan Perikanan (Permen KP) No. 44 Tahun 2016 tentang 
Penyelenggaraan Kehumasan di lingkungan KKP. Peraturan ini menjadi panduan bersama dalam mengimplementaikan dan menjabarkan program kerja pada masing masing unit kerja esselon 1 yang berada di KKP.

\section{Identifikasi Masalah}

Meninjau kondisi yang ada di Badan Riset dan Sumber Daya Manusia Kelautan dan Peirkanan (BRSDM)-Kementerian Kelautan dan Perikanan khususnya di dalam melaksanakan kegiatan kehumasan maka perlu menggambarkan beberapa permasalahan sebagai berikut :

1. Kegiatan kehumasan apa saja yang dilakukan berdasarkan Permen KP No. 44 Tahun 2016 tentang Penyelenggaraan Kehumasan di lingkungan KKP;

2. Bagaimana Peran Humas BRSDM berdasarkan Permen KP No. 44 Tahun 2016 tentang Penyelenggaraan Kehumasan di lingkungan KKP dan tugas fungsi BRSDM yang tertuang dalam Permen KP Nomor 6/Permen-KP/2017;

\section{Metode Penelitian}

Penelitian ini menggunakan metode deskriptif, dimana penulis ingin menberikan deskripsi/gambaran secara faktual tentang situasi/kondisi kehumasan dan menerangkan hubungan untuk mendapatkan tujuan pada suatu masalah yang ingin dipecahkan yang berada di BRSDM. Beberapa teori tentang penelitian deskiptif antara lain menurut Whitney (1960: 160) metode deskriptif adalah pencarian fakta dengan interpretasi yang tepat dan Sugiyono (2005: 21) menyatakan bahwa metode deskriptif adalah suatu metode yang digunakan untuk menggambarkan atau menganalisis suatu hasil penelitian tetapi tidak digunakan untuk membuat kesimpulan yang lebih luas.

Metode ini sangat sederhana dan banyak digunakan khususnya para penliti muda untuk melaporkan objek dan subjek yang ditelitinya secara lebih kompleks melalui pengamatan soail yang natural dan apa adanya.

Penelitian deskriptif dipilih untuk mendeskripsikan dan mengidentifikasikan kondisi di humas Kementerian Kelautan dan Perikanan dan humas BRSDM khususnya serta Peraturan Menteri Kelautan dan Perikanan.

Penelitian deskriptif ini ditujukan dalam penyusunan makalah ini (Rakhmat, 2016) mellaui beberapa tahapan diantaranya adalah:
1. Mengumpulkan data dan informasi secara terperinci yang melukiskan gejala yang ada;

2. Mengidentifikasi masalah aau memeriksa kondisi dan praktik-praktik yang berlaku;

3. Membuat perbandingan atau evaluasi;

4. Menentukan apa yang dilakukan dalam menghadapi permasalahan dan menetapkan rencana serta keputusan pada waktu yang akan datang.

\subsection{Maksud dan Tujuan Riset}

\subsubsection{Maksud Riset}

Maksud dari riset ini adalah untuk mengetahui secara lebih lanjut mengenai mengetahui dan menemukan betapa pentingnya dan besarnya peranan dan kegiatan yang telah di lakukan oleh Tim Humas BRSDM sesuai Peraturan Menteri KP No 44 Tahun 2016 tentang Penyelenggaraan Kehumasan di Lingkungan KKP.

\subsection{Kegunaan Riset}

\subsubsection{Kegunaan Teoritis}

Melalui tulisan ini, penulis mengharapkan agar;

1. Tim Humas BRSDM dapat lebih maksimal dan bermotivasi dalam menjalankan perannya sebagai Humas BRSDM sesuai tugas fungsi yang ada di Peraturan Menteri Kelautan dan Perikanan Nomor 6/Permen-KP/2017,tentang Organisasi Dan Tata Kerja Kementerian Kelautan Dan Perikanan dan Peraturan Menteri KP No 44 Tahun 2016 tentang Penyelenggaraan Kehumasan di Lingkungan KKP.

2. Peran Humas BRSDM dapat menjadi tolak ukur bagi pengelola humas di lingkup eselon I pada lingkungan BRSDM lainnya.

3. Kegiatan kehumasan makin variasi atau beragam lagi sesuai peraturn yang berlaku;

\subsubsection{Kegunaan Praktis}

Untuk Kantor BRSDM, dapat digunakan sebagai masukan pemikiran bagi pimpinan tertinggi untuk lebih membeikan perhatian untuk kelancaran Humas BRSDM dalam menjalankan pelayanan informasi kepada publik dan memberikan citra positif.

\section{TINJAUAN PUSTAKA}

Humas memiliki beragam definisi, salah satu contoh definisi humas menurut Dominick (2000), dalam pekerjaannya memiliki kaitan dengan opini publik, memiliki kaitan dengan komunikasi dan humas merupakan fungsi manajemen. Pekerjaan humas saat ini sangat penting dalam penyampaian pesan kepada masyarakat bukan hanya mengurus wartawan dan 
berhubungan dengan media massa.

Ruang lingkup humas adalah publik eksternal dan internal dari suatu ornganisasi dalam mencapai visi dan misi suatu organisasi. Semakin luas komponen publik yang berkepentingan terhadap organisasi, maka elemen publiknya juga aski luas, semakin beragam dan permasalahannya juga semakin kompleks (Morrison, 2010).

Definisi tentang humas/public relation yang menjadi acuan diambil dari The British of Public $R e$ lation, diantaranya: "Aktifitas Public Relation adalah mengelola kounikasi antara organisasi dan publiknya" dan "Praktik Public Relation adalah memikirkan, merencanakan dan mencurahkan daya untuk membangun dan menjaga saling pengertian antara organisasi dan publiknya".

Definisi humas yang diterbitkan oleh International Public Relation assosiation (IPRA) 1978, dalam bukunya yang berjudul $A$ Model for Public Relatio Education for Professional Practices, menurut Dr. Rex Harlow definisi Public Relation adalah fungsi manajemen yang khas dan mendukung pembinaan, pemeliharaan jalur bersama antara organisasi dengan publiknya, menyangkut aktivitas komunikasi, pengertian, penerimaan dan kerja sama; melibatkan manajemen untuk menghadapi persoalan/ permasalahan, membantu manajemen untuk mampu menanggapi opini publik; mendukung manajeman dalam mengikuti dan memanfaatkan perubahan secara efektif; bertindak sebagai sistem peringatan dini dalam mengantisipasi kecenderungan penggunaan penelitian serta teknik komunikasi yang sehat dan etis sebagai sarana utama (Harlow, 1978)

Dalam buku Ruslan (2012), dari beberapa teori definisi dan fungsi mengenai humas/public relation dapat ditarik kesimpulan bahwa proses dan fungsi manajeman humas/public relation,adalah:

1. Menunjukkan kegiatan tertentu (action);

2. Kegiatan yang jelas (activities);

3. Adanya perbedaan khas dengan kegiatan lain (different);

4. Terdapat suatu kepentingan tertentu (important);

5. Adanya kepentingan bersama (common interest);

6. Terdapat komunikasi dua arah timbal balik (reciprocal two ways traffic communication);

Teori tersebut menunjukkan fungsi manajerial dalam suatu organisasi yaitu pembagian tugas, wewenang dan tanggung jawab yang jelas yaitu klasifikasi pimpinan dan klasifikasi bawahan. Menurut G.R. Terry, 1972: Management is a Communication (dalam buku Rosady Ruslan, 2012: Manajemen Public Relation dan Media Komunikasi), dalam hal penyampaian instruksi di satu pihak, dan pelaksanaan kewajiban di lain pihak. Dengan kata lain manajeman komunikasi adalah alat, bukan merupakan tujuan dari suatu organisasi. Pola strategi komunikasi dan pelaksanaan fungsi manajemen dalam suatu organisasi berdasarkan: Plan, Do, Chek and Action Plan (Gambar 1).

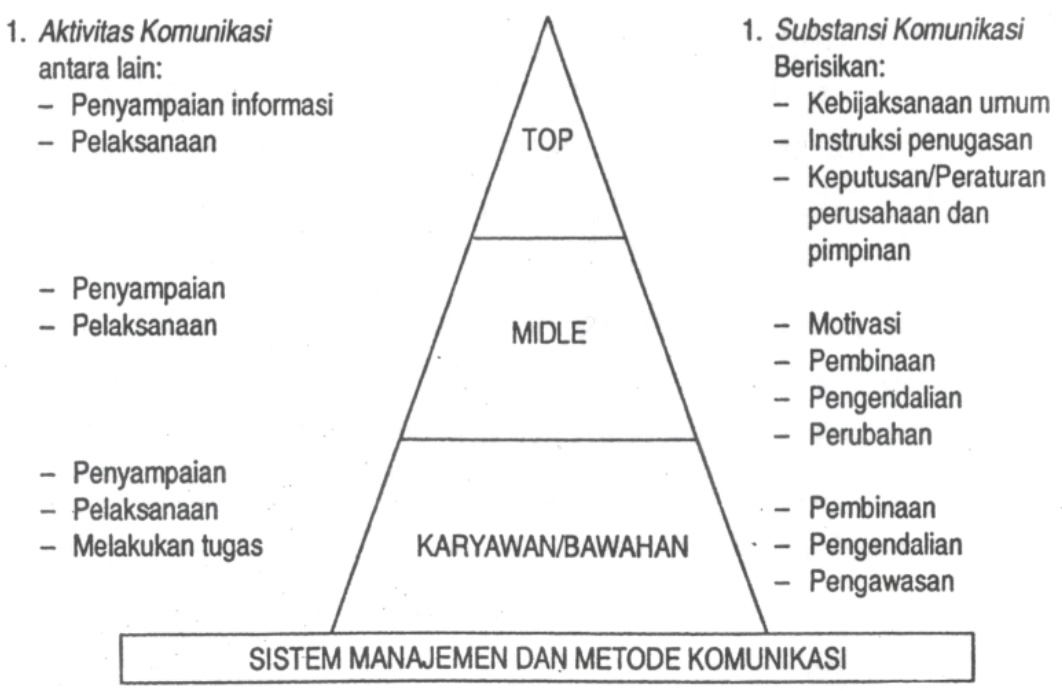

Gambar 1. Sistem Manajemen dan Metode Komunikasi (G.R Terry)

Komunikasi yang mengatur alur informasi dalam suatu organisasi membutuhkan suatu manajemen yang kemudian diatur dalam manajeman kehumasan. Kualitas komunikasi pemerintah ditentukan oleh manajemen kehumasan yang ditetapkan oleh suatu organisasi pemerintah. Manajemen kehumasan yang tertuang dalam tulisan berisi tentang kebijakan, ide/ gagasan dan keputusan yang dapat menaungi seluruh 
organisasi di dalamnya.

Komunikasi organisasi menurut Pearson (2011) dalam mendefinisikan yaitu "Organizational communication as the ways in which groups of people both maintain structure and order through their symbolic interactions and allow individual actors the freedom to accomplish their goals" (Komunikasi organisasi sebagai cara di mana sekelompok orang mempertahankan struktur dan ketertiban melalui interaksi simbolik mereka dan memberikan kebebasan bagi setiap individu untuk mencapai tujuan merek). Dijelaskan bahwa komunikasi adalah salah satu alat utama untuk merubah suatu organisasi dalam mencapai tujuan sesuai dengan jenis organisasi yang terbentuk.

Komunikasi organisasi sama halnya dengan komunikasi pemerintah adalah bagian dari suatu kelompok formal. Pengertian komunikasi pemerintah menurut Erliana Hasan (2005) Komunikasi pemerintahan adalah penyampaian ide, program, dan gagasan pemerintah kepada masyarakat dalam rangka mencapai tujuan begara.

Dalam penyampaian komunikasi pemerintah dibutuhkan peran humas pemerintah didalam organisasi pemerintah untuk penyebaran informasi kepada publik.

Peran humas pemerintah dalam menjalankan pelayanan informasi terdapat beberapa kendala diantaranya fungsi manajemen, kepemimpinan, keterbatasan jumlah dan kompetensi SDM, kekurangan fasilitas komunikasi, dan kekurangan informasi dan pengetahuan.

Dalam menjawab permasalahan diatas, menurut (Baker: 1997) diperlukan beberapa strategi dasar yang berfokus untuk mencapai tujuan humas pemerintah diantaranya;

1. Melakukan komunikasi politik;

2. Melayani informasi;

3. Membentuk citra positif institusi,;

4. Merangkul umpan balik dari publik.

Kebijakan Kementerian Kelautan dan Perikanan (KKP) untuk mencapai tujuan humas pemerintah telah dituang dalam Peraturan Menteri Kelautan dan Perikanan (Permen KP).

Peraturan Menteri Kelautan dan Perikanan Nomor 6 / Permen-KP / 2017 tentang Organisasi Dan Tata Kerja Kementerian Kelautan Dan Perikanan
Peraturan Menteri Kelautan dan Perikanan (Permen KP) Nomor 6/ Permen-KP/2017 tentang Organisasi Dan Tata Kerja Kementerian Kelautan Dan Perikanan ditetapkan pada tanggal 30 Januari 2017 dan diundangkan pada tanggal 3 Februari 2017. Perauran ini menjabarkan tentang penyelenggaraan pemerintahan di bidang kelautan dan perikanan dalam membantu presiden dalam menyelenggaraan pemerintahan negara.

\section{Peraturan Menteri KP No 44 Tahun 2016 tentang Penyelenggaraan Kehumasan di Lingkungan KKP}

Peraturan Menteri KP (Permen KP) No 44 Tahun 2016 tentang Penyelenggaraan Kehumasan di Lingkungan KKP ditetapkan oleh Menteri Keluatan dan Perikanan Ibu Susi Pudjiastuti pada tanggal 8 Desember 2016 dan diundangkan pada tanggal 9 Desember 2016. Perauran ini menjabarkan tentang kegiatan kehumasan pada masing-masing eselon 1 juga sebagai acuan di lingkungan KKP.

Dan menyamakan presepsi dan memberikan arah dalam melaksanakan kehumasan di lingkungan KKP sebagai media komunikasi dan pemberi informasi. Peraturan ini menjadi panduan pada pembuatan kerangka acuan kerja .

\section{OBJEK RISET}

Badan Riset dan Sumber Daya Manusia Kelautan dan Perikanan (BRSDM) mempunyai struktur organisasi dan juga struktur birokrasi yang tertata dengan baik, diatur oleh Peraturan Menteri Kelautan dan Perikanan Nomor 6/PERMEN-KP/tentang Organisasi Dan Tata Laksana Kementerian Kelautan dan Perikanan.

BRSDM merupakan unit eselon 1 Kementerian Kelautan dan Perikanan berada dibawah dan bertanggung jawab kepada Menteri dan dipimpin oleh Kepala Badan. Kepala Badan, dan dibantu oleh Eselon 2 lainnya yaitu Sekertaris BRSDM dan Kepala Pusat Riset lingkup BRSDM.

Sekretariat BRSDM dengan tugas pokok melaksanakan pelayanan teknis dan administratif kepada satuan organisasi lingkup badan. Sekretariat BRSDM terdiri dari 4 Bagian yaitu Bagian Program, Bagian Sumber Daya Manusia Aparatur, Hukum, dan Organisasi, Bagian Keuangan dan Umum serta Bagian KerjaSama, Hubungan Masyarakat, dan Data (Bagian KHD). 
Dalam penyebaran informasi, BRSDM memiliki satuan kerja yang melakukan publikasi dan promosi tentang kegiatan yang dilakukan oleh Sekretariat BRSDM. Sekretariat BRSDM melalui Bagian Kerja Sama, Hubungan Masyarakat dan Data melaksanakan hubungan masyarakat, pengelolaan dan penyelenggaraan informasi publik, pengelolaan perpustakaan yang dilakukan oleh Subbagian Hubungan Masyarakat (Humas).

Sistem pemerintahan tak lepas dari kebutuhan komunikasi dan informasi, maka Sub Bagian Humas di Sekretariat BRSDM melakukan beberapa aktifitas antara lain pelayanan publik, pengelolaan perpustakaan, pameran, peliputan, penulisan artikel (siaran pers)untuk publikasi media luar dan internal (website, twitter, instagram dan facebook).

Tugas Subbagian Humas Sekretariat BRSDM melakukan tugas antara lain;

(1) Penyusunan siaran pers terkait kebijakan dan kegiatan BRSDM agar mempunyai nilai berita untuk dipublikasikan kepada media massa;

(2) Pengelolaan Media Sosial (twitter, instagram dan facebook) BRSDM sebagai media penghubung dan penyampai pesan dengan khalayak BRSDM secara cepat dan realtime;

(3) Kontrol media sosial lingkup BRSDM: Subbagian Humas bertugas menentukan Agenda Setting untuk media sosial yang digunakan oleh UPT lingkup BRSDM agar terjadi sinergi pesan yang disampaikan kepada khalayak dan stakeholders BRSDM;

(4) Editing video dan motion grafis BRSDM: Subbagian Humas bertugas mengolah dokumentasi video dan konten grafis agar pesan yang dikomunikasikan kepada khalayak dan stakeholders BRSDM lebih mudah diterima dan dipahami;

(5) Pelayanan Publik, koordinator pelayanan publik lingkup BRSDM: Subbagian Humas bertugas menjadi koordinator dalam kegiatan Pelayanan Publik lingkup BRSDM sesuai dengan semangat Reformasi Birokrasi di KKP;

(6) Pameran, promosi dan publikasi hasil hasil riset, pendidikan dan pelatihan: Subbagian Humas bertugas melakukan pameran, promosi dan publikasi hasil riset maupun kegiatan BRSDM untuk mempercepat penyampaian informasi hasil riset dan kegiatan BRSDM kepada khalayak umum;

(7) AMAFRAD Press, penerbitan dan pencetakan publikasi BRSDM: Subbagian Humas BRSDM menyelenggarakan AMAFRAD Press yang bertugas melakukan operasional AMAFRAD Press mulai dari menghimpun naskah, menyunting dan mendistribusikan bahan publikasi lingkup BRSDM. AMAFRAD Press dibentuk dengan tujuan mewadahi hasil publikasi lingkup BRSDM baik berbentuk cetakan maupun elektronik sekaligus memberi nilai tambah pada hasil terbitan publikasi dimaksud.

(8) Pengelolaan perpustakaan BRSDM: Subbagian Humas bertugas mengelola perpustakaan Sekretariat BRSDM serta sebagai koordinator kegiatan lingkup kepustakaan di BRSDM.

Garis besar tugas dan fungsi Subbagian Hubungan Masyarakat memiliki peran sangat penting sebagai corong kehumasan di BRSDM, selain pelayanan publik dan perpustakaan. Tugas dan fungsi kehumasan telah diatur melalui Peraturan Menteri Keluatan dan Perikanan.

Tugas dan fungsi tim humas mengikat pada peraturan Menteri Kelautan dan Perikanan yaitu Peraturan Menteri Kelautan dan Perikanan Nomor 6 / Permen-KP / 2017 tentang Organisasi Dan Tata Kerja Kementerian Kelautan dan Perikanan dan Peraturan Menteri KP No 44 Tahun 2016 tentang Penyelenggaraan Kehumasan di Lingkungan KKP (Gambar 2).

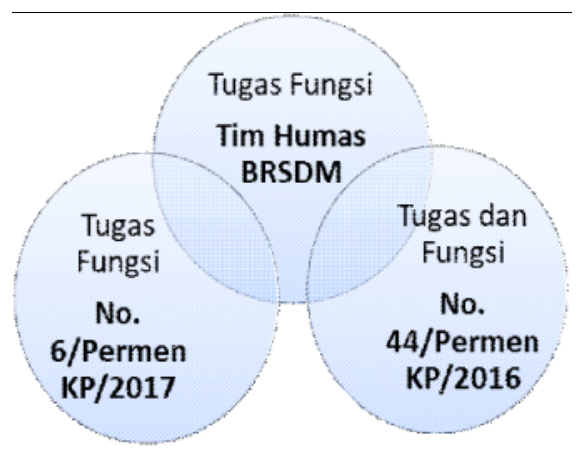

Gambar 2. Korelasi Tugas dan Fungsi Kehumasan di BRSDM

Keterkaitan tugas dan fungsi tersebut pada Subbagian Humas menjadi dasar dalam melakukan koordinasi pada unit kerja lingkup BRSDM yang menangani kehumasan atau pelayanan teknis dengan melakukan beberapa seminar, lokakarya, bimbingan teknis dan sebagainya tentang kehumasan.

\section{Pembahasan}

Staf Humas harus bekerja sama secara erat dengan unit kerja kehumasan di lingkup BRSDM untuk mencapai tujuan yaitu menciptakan saling pengertian dan dukungan untuk menciptakan tujuan, kebijakan dan langkah/tindakan bagi BRSDM. Berdasarkan F Rachmadi (1994), tujuan tersebut 
untuk memperoleh opini publik yang menguntungkan atau untuk menciptakan kerjasama berdasarkan hubungan yang harmonis dengan publik.

Praktisi Humas harus menetapkan prioritas tujuan dengan beberapa pertimbangan yang akan dicapaiantara lain; mempertimbangkan sumber daya yang tersedia, mengutamakan tujuan jangka panjang, dan memepertimbangkan jumlah dana yang tersedia. Seperti yang dipaparkan Kasali bahwa proses hubungan masyarakat/publik relation bukan sematamata memiliki tugas yang melakukan aksi, melainkan membutuhkan rencana-rencana dan diikuti langkahlangkah pengendalian melalui prose evaluasi.

Humas BRSDM memegang peranan penting dalam menyebarkan informasi hasil riset, pendidkan, pelatihan dan penyuluhan kelautan dan perikanan kepada masyarakat untuk mendukung pemerintah dalam keterbukaan informasi publik.

Subbag Humas memiliki tugas yaitu melakukan penyiapan bahan koordinasi pelaksanaan hubungan masyarakat, pemberitaan, peliputan, pembuatan infografis dan videografis, pengelolaan dan pelayanan informasi publik, dan pengelolaan perpustakaan, pencetakan AMAFRAD Press, dan pameran.

Peraturan Menteri Kelautan dan Perikanan Nomor. 6/Permen-KP/2017 tentang Organisasi Dan Tata Kerja Kementerian Kelautan dan Perikanan, menjelaskan salah satu fungsi Bagian Kerja Sama, Hubungan Masyarakat Dan Data yaitu penyiapan bahan koordinasi pelaksanaan hubungan masyarakat, pengelolaan dan pelayanan informasi publik, dan pengelolaan perpustakaan; dan tugas Subbagian Hubungan Masyarakat melakukan penyiapan bahan koordinasi pelaksanaan hubungan masyarakat, pengelolaan dan pelayanan informasi publik, dan pengelolaan perpustakaan"

Peran Tim humas BRSDM telah melakukan tugas dan fungsi sesuai dengan Permen KP No.44/2016 tentang Penyelenggaraan kehumasan di lingkungan KKP pada pasal 5 dan 31 ayat 2 dan 4 .

Dalam pelaksanaan kegiatan kehumasan BRSDM yang dilakukan tim humas terdapat 10 item berdasarkan pasal 5 dan 31 diantarannya adalah;

1. menyelenggarakan konferensi pers;

2. menyusun dan menandatangani siaran pers;

3. melaksanakan liputan;

4. melakukan publikasi;

5. menerbitkan dan mendistribusikan media internal berupa jurnal ilmiah/terbitan berkala ilmiah, tabloid, buletin, brosur, leaflet, booklet, poster kalender, buku agendakerja, dan/atau media lain yang dianggap perlu;

6. menyusun dan menayangkan advetorial dan iklan;

7. melaksanakan pameran;

8. menyelenggarakan orientasi humas;

9. mengelola kliping;

10. mengelola media online atau media dalam jaringan (daring).

Beberapa tugas dan fungsi BRSDM yang merupakan tugas kehumasan Eselon I yang belum dilakukan tim humas BRSDM terdapat 4 item, antara lain;

1. menyelenggarakan keterangan pers;

2. menyelenggarakan orientasi wartawan;

3. menyiapkan bahan dialog televisi dan radio;

4. melaksanakan orientasi humas;

5. melaksanakan kampanye kehumasan;

Dan tugas dan fungsi BRSDM yang merupakan tugas kehumasan Eselon I yang tidak bisa dilakukan tim humas BRSDM adalah menyelenggarakan wawancara Pers (keterangan pada gambar 2).

Mengacu pada permen KP No.44/2016 tentang Penyelenggaraan kehumasan di lingkungan KKP, kegiatan tim Humas BRSDM telah melakukan $60 \%$ dari total seluruh kegiatan.

Kegiatan kehumasan BRSDM tidak dituangkan dalam Peraturan Menteri KP No.44/2016 adalah yang mengatur pelayanan publik dan perpustakaan.

\section{KESIMPULAN}

Tugas dan fungsi humas BRSDM selama ini masih kalah dibandingkan dengan kehumasan/public relation organisasi bisnis atau kalangan swasta lainnya sehingga peran kehumasan sangat diandalakan.

Tugas dan fungsi manajeman tim humas/public relation BRSDM, telah menunjukkan kegiatan (action) dan kegiatan (activities) yang jelas seperti yang telah jelas dijabarkan dan sesuai dengan Peraturan Menteri Kelautan dan Perikanan Nomor 6 /Permen-KP / 2017tentang Organisasi Dan Tata Kerja Kementerian Kelautan Dan Perikanan dan Peraturan Menteri KP No 44 Tahun 2016 tentang Penyelenggaraan Kehumasan di Lingkungan KKP.

Humas BRSDM merupakan Humas pemerintah dalam menjalankan pelayanan informasi sudah maksimal dan berjalan dengan baik sesuai Permen KP No.44/2016 dan No.6/Permen-KP/2017, walaupun dalam pelaksanaan kehumasan masih terdapat beberapa kendala dan hambatan. 
Masih ada beberapa kendala dalam pelaksanaan tugas dan fungsi yang belum dilakukan diharapkan dapat dilakukan dengan memberi kesempatan bagi tim humas BRSDM untuk melaksanakan kegiatan tersebut. Kegiatan tersebut tentu saja dibawah pengawasan dan instruksi dari pimpinan tertinggi untuk mencapai tujuan yang diharapkan.

Tim Humas BRSDM diharapkan dapat dilibatkan dalam memutuskan suatu kebijakan tertentu sangat penting, karena humas merupakan pemegang informasi yang lengkap mengenai publik-publik dari organisasi pemerintahnya yaitu BRSDM, dan peran humas dalam memainkan peranan sebagai penyedia informasi dapat dipertanggungjawabkan sehingga dapat diawasi oleh pubik.

Tim humas BRSDM juga harus dapat meningkatkan sumber daya manusia yang ada melalui pelatihan kehumasan untuk meningatkan kompetensi untuk menunjang tugas dan fungsi kehumasan secara maksimal.

Hasil kegiatan kehumasan yang telah dihasilkan diharapkan dapat menjadi acuan bagi unit kehumasna lingkup BRSDM, membentuk citra positif BRSDM.

\section{DAFTAR PUSTAKA}

Caywood, clarke L. 1997. The Hanbook of Strategic Public Relation and Integrated Communication. McGaw-Hill

Effendy, Onong Uchjana. 2003. IImu, Teori dan Filsafat Komunikasi. Bandung: PT. Citra Aditya Bakti.

Erliana Hasan. 2005. Komunikasi Pemerintahan, Bandung: Refika Aditama Fahri, dkk.2006. Komunikasi Islam. Yogyakarta: AK Group

F.L,Whitney.1960. The Elements of Resert.Asian Eds. Osaka: Overseas Book Co.

Kasali, Rhenald. 1994. Manajemen Public Relation, Konsep dan Aplikasinya di Indonesia. Jakarta: Pustaka Utama Grafiti.

Isaac, S. Dan W.B. Michael, 1981. Handbook in Research and Evaluation. San Diego: Edits Publishers.

Morissan, M.A. 2010. Manajemen Public Relation: Strategi Manjadi Humas Profesional. Jakarta: Kencana
Moore, H. Frazie. 1981. Humas: Membangun Citra Dengan Komuniksi. Bandung: PT Remaja Rosdakarya.

Myers, G.E. \& Myers. M.T 1987, Teori-teori Manajemen Komunikasi, ,Jakarta: Bahana Aksara.

Pearson, Judy C, dkk. 2011: Humasn Communication, USA: McGraw-Hill Humanities/ Social Sciences/Languages

Rakhmat, Jalaluddin. 2016. Metode Penelitian Komunikasi (edisi kedua). Bandung: PT Remaja Rosdakarya.

Rakhmat, Jalaluddin. 2011. Psikologi Komunikasi. Bandung: PT Remaja Rosdakarya.

Rakhmat, Jalaluddin. 1986. Teori-teori Komunikasi. Bandung: PT Remaja Karya.

Rachmadi, F. 1994. Public Relation dalam Teori dan Praktek. Jakarta: Galamedia Pustaka Utama

Ruslan, Rosady. 1995. Praktik dan Solusi Public Relations Dalam Situasi Krisis dan Pemulihan Citra. Jakarta: Ghalia Indonesia

Ruslan, Rosady. 1995. Aspek-aspek Hukum dan Etika dalam Aktivitas Public Relations/ Kehumasan. Jakarta: Ghalia Indonesia

Ruslan, Rosady. 1997. Kiat dan Strategi Kampanye Public Relation. Jakarta: PT Raja Grafindo Persada.

Ruslan, Rosady. 2012. Manajemen Public Relation dan Media Komunikasi: Konsep dan Aplikasi. Jakarta: PT Raja Grafindo Persada.

Soemirat, Soleh. 2012. Dasar-Dasar Public Relations. Bandung: PT Remaja Rosdakarya.

Sugiyono. 2011. Metode Penelitian Bisnis. Bandung: Alfabeta.

Yusuf, Pawit.M. 2009. Ilmu Informasi, Komunikasi, dan Kepustakaan. Jakarta: Bumi Aksara.

Undang-undang dan Dokumen:

1. Peraturan Menteri KP No 44 Tahun 2016 tentang Penyelenggaraan Kehumasan di Lingkungan KKP.

2. Peraturan Menteri Kelautan dan Perikanan Nomor 6 / Permen-KP / 2017 tentang Organisasi Dan Tata Kerja Kementerian Kelautan Dan Perikanan 